\title{
Correlation of Renal Colic Incidences with the Season, Gender and Age: Cross-Sectional Study
}

\author{
๑ Aytaç Şahin ${ }^{1}, \odot$ Ahmet Ürkmez ${ }^{2}, \odot$ Çağlar Yıldırım³ ${ }^{3}, \odot$ Serkan Akan $^{4}, \odot$ Doğu Güner ${ }^{1}$, \\ (1) Özgür Haki Yüksel ${ }^{5}$ \\ ${ }^{1}$ Department of Urology, Fatih Sultan Mehmet Training and Research Hospital, Istanbul, Turkey \\ ${ }^{2}$ Department of Urology, University of Health Sciences, Hamidiye Faculty of Medicine, Haydarpasa Numune Health Application and \\ Research Center, Istanbul, Turkey \\ ${ }^{3}$ Department of Urology, Mardin State Hospital, Mardin, Turkey \\ ${ }^{4}$ Department of Urology, Sultan Abdulhamid Han Training and Research Hospital, Istanbul, Turkey \\ ${ }^{5}$ Department of Urology, Bahcesehir University, Istanbul, Turkey
}

\begin{abstract}
Introduction: In the present study, we researched whether meteorological changes affect the number of renal colic patients admitted to the hospital emergency department and whether this effect varies with gender and age.

Methods: In this study, 5661 patients admitted to the emergency medicine clinic of Fatih Sultan Mehmet Training and Research Hospital between the dates of January 2017 and December 2017 with renal colic complaints were retrospectively scanned with International Classification for Diseases- 10 (ICD 10) N23 (renal colic) code. Renal colic was diagnosed and treated by emergency medicine physicians. Average temperature and humidity values according to months were acquired from the Republic of Turkey Ministry of Forestry and Water Affairs General Directorate of Meteorology.

Results: This study was conducted with a total number of 5661 cases between the ages of 2 and 91.3344 (59.1\%) of the patients were male, and 2317 (40.9\%) were female. The average examination age of the cases was $41.58 \pm 14.63$. There was a statistically significant difference between the seasons in terms of the examination ages of the cases $(p=0.001)$. As a result of the dual comparisons, the average examination age of the cases in the summer season was found to be lower at a statistically significant level than the averages of the cases in Winter $(p=0.001)$, Spring $(p=0.001)$ and Fall $(p=0.045)$ seasons $(p<0.05)$. Discussion and Conclusion: In our study, we detected that meteorological parameters have an effect on renal colic development, and this effect varies according to the age and gender of the patient. Especially in the warmer months, male patients are more sensitive towards dehydration than female patients, probably due to the hormonal mechanisms, so the renal colic incidence is higher in these patients. Thus, the suggestion is to increase fluid intake and not to stay dehydrated.

Keywords: Age; gender; meteorological parameters; renal colic; season.
\end{abstract}

$\mathrm{R}_{\mathrm{s}=\mathrm{s}}$ enal colic is a frequently encountered urologic emergency condition that frequently develops related to kidney stone disease and diagnosed and treated in emergency departments and which emerges with severe pain. Renal colic frequently begins as a sudden pain that does not go away without treatment due to the obstruction of the upper urinary system. The cause is urolithiasis in $85 \%$ of the cases ${ }^{[1]}$. Approximately 600.000 patients are admitted to Emergency Services Departments annually in the USA. ${ }^{[2]}$.

The risk of a person going through a renal colic attack

Correspondence (İletişim): Ahmet Urkmez, M.D. Saglik Bilimleri Universitesi Hamidiye Tip Fakultesi, Haydarpasa Numune Saglik Uygulama ve Arastirma Merkezi, Uroloji Anabilim Dali, Istanbul, Turkey

Phone (Telefon): +90 5077668300 E-mail (E-posta): ahmeturkmez@hotmail.com

Submitted Date (Başvuru Tarihi): 15.06.2018 Accepted Date (Kabul Tarihi): 07.08.2018

Copyright 2020 Haydarpaşa Numune Medical Journal

OPEN ACCESS This is an open access article under the CC BY-NC license (http://creativecommons.org/licenses/by-nc/4.0/)

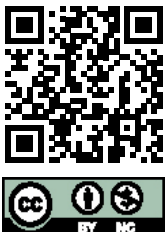


throughout their entire life is between $1-10 \%{ }^{[3]}$. Stone disease incidence rate is approximately $15 \%$ in Turkey ${ }^{[4]}$. Male to female ratio is approximately 3-4:1 ${ }^{[5]}$. It usually peaks around the age of 30 in men, and at the ages of 35 and 55 in women ${ }^{[6]}$. We should note that $5-12 \%$ of the population has the possibility of experiencing renal colic due to stone in some period of their lives ${ }^{[7]}$. If untreated, its relapse rate may go up to $30 \%-40 \%$, while reoccurrence can be reduced with diet and appropriate pharmacologic treatments at rates reaching $50 \%{ }^{[8,9]}$. Costovertebral angle sensitivity is an important symptom in renal colic during the physical examination. Usually, microscopic hematuria, nausea and vomiting accompany colic pain. There is a pressure increase in the urinary tract due to the stone preventing the urine flow. Edema and inflammation occur around the stone, causing an obstruction. Diuresis increases because of the prostaglandin excretion, and it increases the spasmodic effect on ureteral smooth muscle and increases the severity of renal colic ${ }^{[10,11]}$.

Stone formation is a complex process that begins with crystallization and goes on to crystal formation with crystal growth, aggression and adhesion. This process continues with the addition of some chemical and environmental factors which have stimulant or repressive effects. Climate and temperature are also among the environmental factors which have stimulant effects on stone formation. A relationship between renal colic frequency and temperature increase is stated in many studies ${ }^{[13-16]}$, but in some studies, there was not a statistically significant relationship detected between this couple $[17,18]$. In this study, we researched whether meteorological changes have an effect on the number of renal colic patients admitted to the emergency departments and also whether this effect varies between genders and among years of age.

\section{Materials and Methods}

Five thousand six hundred sixty-one patients admitted to the Fatih Sultan Mehmet Training and Research Hospital emergency medicine clinic between the dates of January 2017and December 2017 with renal colic complaints were retrospectively scanned with International Classification for Diseases- 10 (ICD 10) N23 (renal colic) code. Patients who were admitted with abdominal-flank pain complaints but were later diagnosed with diseases outside of the urinary tract stone disease, such as acute appendicitis, ovarian torsion, pelvic inflammatory disease, were excluded from this study. Renal colic was diagnosed and treated by emer- gency medicine physicians. Patients with repeated hospital visits were included in this study. Temperature and humidity values according to months were acquired from the Republic of Turkey Ministry of Forestry and Water Affairs General Directorate of Meteorology.

\section{Statistical Analyses}

IBM SPSS Statistics 22 program was used in the evaluation of the results acquired in this study. The compatibility of the parameters with normal distribution was evaluated using the Shapiro Wilks test in the evaluation of the study data. During the evaluation of the study data, on top of the descriptive statistical methods (Mean, Standard deviation, frequency), in the comparison of quantitative data, OneWay ANOVA test was used in the comparison of parameters showing normal distribution between the groups and Tamhane's T2 test was used in the detection of the group causing the difference. Kruskal Wallis test was used in the comparison of the parameters not showing normal distribution between the groups and the Mann-Whitney $U$ test was used in the detection of the group causing the difference. Chi-Square test was used in the comparison of qualitative values. Significance was evaluated at $p<0.05$ level.

\section{Results}

This study was conducted on a total of 5661 cases with examination ages between 2 and 91 between the dates of January $1^{\text {st }}, 2017$ and December 31 ${ }^{\text {st }}, 2017.3344$ (59.1\%) of the cases were male, and 2317 (40.9\%) were female. The average examination age of the cases was $41.58 \pm 14.63$. There was a statistically significant difference concerning the gender distribution rates of the cases admitted to the emergency department between the seasons $(p=0.044$; $\mathrm{p}<0.05$ ) (Table 1). As a result of the paired comparisons carried out for the detection of the difference, it was found that the ratio of men admitted to the emergency department in fall (61.3\%) was higher than the ratio of men admitted in the seasons of 1 Winter (57.3\%) and 2Spring (56.3\%) while the ratio of women admitted to the emergency department during fall (38.7\%) was found lower at a statistically significant level than the ratios of 1 Winter (42.7\%) and 2Spring (43.1\%) seasons ( $\mathrm{p} 1=0.032$, $\mathrm{p} 2=0.020 ; \mathrm{p}<0.05)$. There was no statistically significant difference found between other seasons in terms of gender distributions ( $p>0.05$ ) (Table 2).

There was no statistically significant difference found between the months concerning the gender distribution ra- 
Table 1. Evaluation of genders according to Months and Seasons

\begin{tabular}{lcc}
\hline & \multicolumn{2}{c}{ Gender } \\
\cline { 2 - 3 } & Male & Female \\
& $\mathbf{n}(\%)$ & $\mathbf{n}(\%)$ \\
\hline Season & & \\
Winter & $771(57.3)$ & $574(42.7)$ \\
Spring & $739(56.9)$ & $559(43.1)$ \\
Summer & $936(60.3)$ & $617(39.7)$ \\
Fall & $898(61.3)$ & $567(38.7)$ \\
p & $0.044^{*}$ & \\
Month & & $189(43.2)$ \\
January & $248(56.8)$ & $188(43)$ \\
February & $249(57)$ & $178(42.4)$ \\
March & $242(57.6)$ & $199(40.9)$ \\
April & $288(59.1)$ & $182(46.5)$ \\
May & $209(53.5)$ & $208(39.1)$ \\
June & $324(60.9)$ & $192(41.4)$ \\
July & $272(58.6)$ & $217(39)$ \\
August & $340(61)$ & $158(34.9)$ \\
September & $295(65.1)$ & $192(39.3)$ \\
October & $297(60.7)$ & $217(41.5)$ \\
November & $306(58.5)$ & \\
December & $274(58.2)$ & \\
p & 0.122 & \\
\hline
\end{tabular}

Chi Square Test; ${ }^{*} \mathrm{p}<0.05$.

Table 2. Evaluation of examination age, temperature and humidity parameters between seasons

\begin{tabular}{|c|c|c|c|}
\hline Season & $\begin{array}{c}\text { Examination age } \\
\text { Mean } \pm S D\end{array}$ & $\begin{array}{c}\text { Temperature } \\
\text { Mean } \pm S D \\
\text { (median) }\end{array}$ & $\begin{array}{c}\text { Humidity \% } \\
\text { Mean } \pm \text { SD } \\
\text { (median) }\end{array}$ \\
\hline Winter & $42.4 \pm 1 J .22$ & $6.8 \pm 1$ & $78.05 \pm$ \\
\hline Spring & $42.69 \pm 14.67$ & $12.05 \pm 3.6(12)$ & $72.42 \pm 1.64(73)$ \\
\hline Summer & $40.06 \pm 14.05$ & $22.98 \pm 1.14(23.8)$ & $69.78 \pm 1.71(69)$ \\
\hline Fall & $41.45 \pm 14.51$ & $15.63 \pm 3.42(15.7)$ & $76.17 \pm 2.91(77)$ \\
\hline$p$ & ${ }^{1} 0.001 *$ & ${ }^{1} 0.001^{*}$ & ${ }^{2} 0.001^{*}$ \\
\hline
\end{tabular}

${ }^{1}$ One-Way Anova Test; ${ }^{2}$ Kruskal Wallis Test; ${ }^{*} \mathrm{p}<0.05$.

tios of the cases admitted to the emergency department ( $p>0.05$ ). There was a statistically significant difference between the seasons about the average examination age of the cases $(p=0.001 ; p<0.05)$. As a result of the paired comparisons carried out for the detection of the difference, the findings showed that the average examination age of the cases in the summer season was lower at a statistically significant level compared to the averages of the cases in Winter $(p=0.001)$, Spring $(p=0.001)$ and Fall $(p=0.045)$ seasons $(p<0.05)$. There was no statistically significant difference between other seasons in terms of the average examination age of the cases $(p>0.05)$.

There was a statistically significant difference between the months concerning the average examination age of the cases $(p=0.001 ; p<0.05)$. As a result of the double comparisons carried out for the detection of the difference, the findings showed that the average examination age of the cases admitted in the month of August was lower at a statistically significant level $(p<0.05)$ than the averages of January $(p=0.002)$, February $(p=0.001)$, March $(p=0.001)$, April $(p=0.001)$, May $(p=0.001)$, July $(p=0.001)$, September $(p=0.041)$, October $(p=0.016)$, November $(p=0.001)$ and December $(p=0.001)$. There was no statistically significant difference found between the other months concerning average examination age of the cases $(p>0.05)$

For men; There was a statistically significant difference between the age groups concerning the distribution ratios of the months $(p=0.001 ; p<0.05)$. As a result of the paired comparisons carried out for the detection of the difference, August distribution ratio of the cases between the ages of 15 and 39 (12.4\%) was found higher at a statistically significant level than the ratios of cases between the ages of 40-59 (8.5\%) and cases at the age of 60 and above (3.6\%) $(p=0.001 ; p<0.05)$. August distribution ratio of the cases between the ages of 40 and 59 (8.5\%) was found higher at a statistically significant level than the ratio of the cases at the age of 60 and above $(3.6 \%)(p=0.002 ; p<0.05)$. There was no statistically significant difference between other age groups in terms of the distribution ratios of the months ( $p>0.05$ ) (Table 3).

\section{Discussion}

Renal colic is a disease frequently observed in emergency departments, and it is characterized by colic type pain. Effects of climate changes on renal colic attacks were researched in countries with different geographical characteristics, and different results were achieved. In most of the studies, it is stated that there is an increase in the frequency of renal colic with the increase of the temperature ${ }^{[13-16,19]}$. There have been some theories derived to explain the relationship between temperature increase and renal colic frequency. One of them is the increase of vitamin D synthesis, and the other theory is the dehydration theory ${ }^{[14-20]}$.

In the vitamin D synthesis theory, the formation of kidney stones is linked to the increase of vitamin D synthesis, 
Table 3. Evaluation of months between separate age groups in males and females

\begin{tabular}{|c|c|c|c|c|c|}
\hline \multirow[t]{2}{*}{ Gender/Month } & \multicolumn{4}{|c|}{ Age } & \multirow[t]{2}{*}{$\mathbf{p}$} \\
\hline & $\begin{array}{c}<15 \\
\mathrm{n}(\%)\end{array}$ & $\begin{array}{l}15-39 \\
n(\%)\end{array}$ & $\begin{array}{l}40-59 \\
n(\%)\end{array}$ & $\begin{array}{c}\geq 60 \\
n(\%)\end{array}$ & \\
\hline \multicolumn{6}{|l|}{ Male } \\
\hline January & $1(7.7)$ & $133(7.3)$ & $90(7.7)$ & $24(7.1)$ & $0.001^{*}$ \\
\hline February & $1(7.7)$ & $136(7.5)$ & $80(6.8)$ & $32(9.5)$ & \\
\hline March & $0(0)$ & $129(7.1)$ & $81(6.9)$ & $32(9.5)$ & \\
\hline April & $0(0)$ & $135(7.4)$ & $118(10.1)$ & $35(10.4)$ & \\
\hline May & $1(7.7)$ & $110(6)$ & $67(5.7)$ & $31(9.2)$ & \\
\hline June & $2(15.4)$ & $194(10.7)$ & $99(8.5)$ & $29(8.6)$ & \\
\hline July & $1(7.7)$ & $158(8.7)$ & $84(7.2)$ & $29(8.6)$ & \\
\hline August & $1(7.7)$ & $226(12.4)$ & $100(8.5)$ & $12(3.6)$ & \\
\hline September & $1(7.7)$ & $146(8)$ & $125(10.7)$ & $23(6.8)$ & \\
\hline October & $1(7.7)$ & $153(8.4)$ & $120(10.2)$ & $23(6.8)$ & \\
\hline November & $2(15.4)$ & $157(8.6)$ & $116(9.9)$ & $30(8.9)$ & \\
\hline December & $2(15.4)$ & $143(7.9)$ & $91(7.8)$ & $37(11)$ & \\
\hline \multicolumn{6}{|l|}{ Female } \\
\hline January & $0(0)$ & $78(8.1)$ & 77 (8.4) & 34 (7.9) & $0.021^{*}$ \\
\hline February & $0(0)$ & $75(7.8)$ & $68(7.4)$ & $45(10.5)$ & \\
\hline March & $0(0)$ & $68(7.1)$ & $82(9)$ & $28(6.5)$ & \\
\hline April & $0(0)$ & $81(8.5)$ & $85(9.3)$ & $33(7.7)$ & \\
\hline May & $0(0)$ & $69(7.2)$ & $76(8.3)$ & 37 (8.6) & \\
\hline June & $0(0)$ & $91(9.5)$ & $73(8)$ & $44(10.3)$ & \\
\hline July & $2(18.2)$ & $74(7.7)$ & $75(8.2)$ & $41(9.6)$ & \\
\hline August & $2(18.2)$ & $114(11.9)$ & $71(7.8)$ & $28(6.5)$ & \\
\hline September & $2(18.2)$ & $70(7.3)$ & $60(6.6)$ & $24(5.6)$ & \\
\hline October & $4(36.4)$ & $84(8.8)$ & $71(7.8)$ & $33(7.7)$ & \\
\hline November & $0(0)$ & $81(8.5)$ & $94(10.3)$ & $42(9.8)$ & \\
\hline December & $1(9.1)$ & $73(7.6)$ & $84(9.2)$ & $39(9.1)$ & \\
\hline
\end{tabular}

Chi Square Test; ${ }^{*} \mathrm{p}<0.05$.

which increases with sunlight ${ }^{[20]}$. In the dehydration theory, stone formation occurs in the urinary system because of the decreased urine volume and increasing crystallization due to inadequate fluid intake and perspiration in hot climates ${ }^{[13-21]}$.

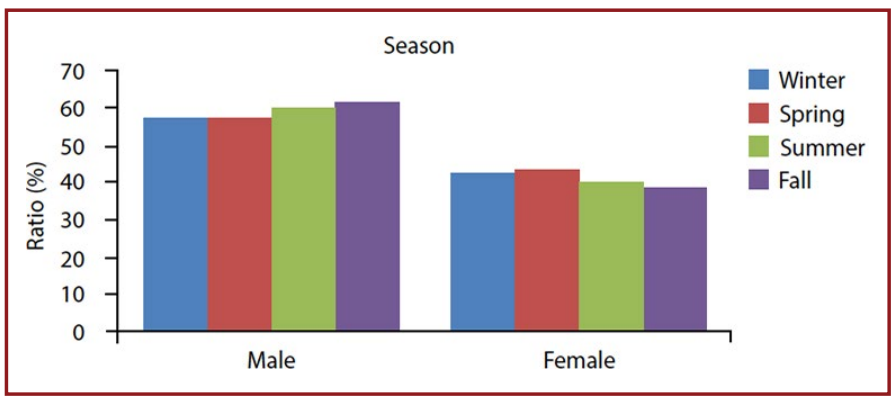

Figure 1. Renal colic incidences according to the seasons between male and female patients.
In a study conducted in the USA, Tom H. Brikowski et al. ${ }^{22]}$ reported that the number of patients who had RC was affected by the temperature and that the rates in the north, south and intercontinental regions were different. A study conducted in Italy by Gervellin et al. ${ }^{[21]}$ using 7-year data of patients determined a strong positive correlation between the number of RC patients in the emergency department and air temperature.

The results of this study show that there is a clear absolute increase in renal colic incidence during the summer months $(27.4 \%)$. This is probably related to the increased average monthly temperatures during the summer. Indeed, this is supported by the important correlation between the number of renal colic patients and the monthly average maximum temperature. Moreover, August had the highest average temperature $(23.8 \mathrm{C})$ and the number of renal colic patients (557-9.8\%).

In some studies, it has been stated that gender and age affect renal colic incidences seasonally while in different studies, it has been stated that there is no such effect. For example, in a study conducted by Pincus et al. ${ }^{[16]}$ in Melbourne, Australia, it was stated that age and gender do not have a clear effect on renal colic incidence seasonally. On the contrary to this, in the New Jersey study, the effect increased with increasing age and was greater in males. In our study, August distribution rate (12.4\%) of the male patients between the ages of 15 and 39 were found higher at a statistically significant level $(p=0001)$ than the cases between the ages of 40 and $59(8.5 \%)$ and cases at the age of 60 and above $(p=0.001 ; p<0.05)$ In a study on US troops in a region with high possibility of renal stones, Evans et al. ${ }^{[23]}$ found that the estimated average duration between formation of kidney stone and symptoms was 93 days. This supports the increased renal colic incidences with the temperature increases starting in May and June, especially in

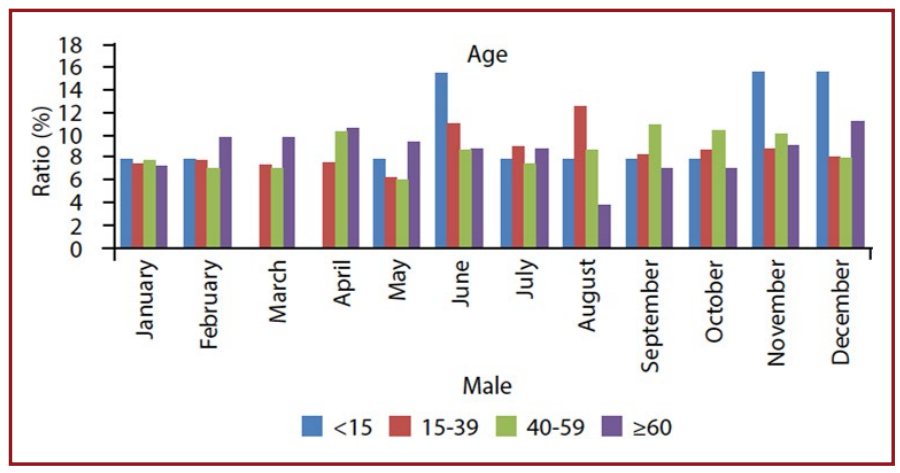

Figure 2. Renal colic incidences according to the months between age groups of $<15,15-39,40-59$, and $>60$ years. 
the month of August in our study. It is believed that the renal colic incidences are more frequent, especially in the 15-39 age group male patients who are more active in daily life due to more fluid loss with perspiration and more exposure to the solar rays.

A negative correlation was determined between daily relative humidity and the number of female RC patients. However, the increase in the number of patients along with temperature increase was found not to be related to gender ${ }^{[24]}$. In our study, there was no statistically significant correlation observed between humidity and seasonal renal colic incidences.

There are several limitations to this study. Cases were selected on their discharge diagnostic code. As this was sometimes based on clinical criteria, rather than examination results, a small number of cases may not have been renal colic. The retrospective nature of the study did not allow determination of whether the cases were presentations arise from by a new stone or recurrent presentations because of a stone that remains unpassed. There may be a delay between renal stone formation and clinical manifestation. In this study, patients were identified by the use of the International Classification of Diseases $10^{\text {th }}$ (ICD-10) revision discharge codes. These codes are assigned based on the discharge diagnosis of the emergency department staff and there may be some variability in how staff identifies renal colic patients. Although there are guidelines on the diagnosis and management of renal colic that are followed by most staff, some patients may have been misclassified.

\section{Conclusion}

While the effects of meteorological parameters on the number of renal colic patients admitted to the emergency departments vary in different studies, in our study, we detected that the meteorological parameters have effects on renal colic development, and this shows variability according to the age and gender of the patients. Although it cannot be more than a comment, since the number of renal colic incidences increases in male patients as they are more sensitive towards dehydration, especially in the warmer months compared to female patients possibly due to hormonal mechanisms, it is suggested to increase liquid intake and not to stay dehydrated.

Ethics Committee Approval: The Ethics Committee of Fatih Sul$\tan$ Mehmet Training and Research Hospital provided the ethics committee approval for this study (KAEK 2017/8).
Peer-review: Externally peer-reviewed.

Authorship Contributions: Concept: A.U.; Design: S.A.; Data Collection or Processing: A.Ş., N.D.G.; Analysis or Interpretation: Ç.Y., Ö.H.Y.; Literature Search: A.Ş.; Writing: A.Ş.

Conflict of Interest: None declared.

Financial Disclosure: The authors declared that this study received no financial support.

\section{References}

1. Valerio M, Doerfler A, Chollet Y, Schreyer N, Guyot S, Jichlinski P. Emergency management of renal colic. Rev Med Suisse 2009;5:2457-61.

2. Pearle MS, Calhoun EA, Curhan GC; Urologic Diseases of America Project. Urologic diseases in America project: urolithiasis. J Urol 2005;173:848-57. [CrossRef]

3. Shokeir AA. Renal colic: pathophysiology, diagnosis and treatment. Eur Urol 2001;39:241-9. [CrossRef]

4. Turkcuer I, Serinken M, Karcioglu O, Zencir M, Keysan MK. Hospital cost analysis of management of patients with renal colic in the emergency department. Urol Res 2010;38:29-33.

5. Worcester EM, Coe FL. Calcium kidney stones. N Engl J Med 2010 2;363:954-63. [CrossRef]

6. Menon M, Resnick MI. Urinary lithiasis etiology, diagnosis and medical management. In: Campbell MF, Walsh PC, Retik AB (editors). Campbell's Urology. 8th ed. Philadelphia, Pa.: Saunders, 2002.

7. Sierakowski R, Finlayson B, Landes RR, Finlayson CD, Sierakowski $\mathrm{N}$. The frequency of urolithiasis in hospital discharge diagnoses in the United States. Invest Urol 1978;15:438-41.

8. Borghi L, Schianchi T, Meschi T, Guerra A, Allegri F, Maggiore U, et al. Comparison of two diets for the prevention of recurrent stones in idiopathic hypercalciuria. N Engl J Med 2002;346:7784. [CrossRef]

9. Johnson CM, Wilson DM, O'Fallon WM, Malek RS, Kurland LT. Renal stone epidemiology: a 25 year study in Rochester, MN. Kidney Int 1979;16:624-31. [CrossRef]

10. Golzari SE, Soleimanpour H, Rahmani F, Zamani Mehr N, Safari $S$, Heshmat $Y$, et al. Therapeutic approaches for renal colic in the emergency department: a review article. Anesth Pain Med 2014;4:e16222. [CrossRef]

11. Holdgate A, Pollock T. Systematic review of the relative efficacy of non-steroidal anti-inflammatory drugs and opioids in the treatment of acute renal colic. BMJ 2004;328:1401. [CrossRef]

12. Davenport K, Timoney AG, Keeley FX. Conventional and alternative methods for providing analgesia in renal colic. BJU Int 2005;95:297-300. [CrossRef]

13. Borghi L, Guerra A, Meschi T, Briganti A, Schianchi T, Allegri F, et al. Relationship between supersaturation and calcium oxalate crystallization in normals and idiopathic calcium oxalate stone formers. Kidney Int 1999;55:1041-50. [CrossRef]

14. Boscolo-Berto R, Dal Moro F, Abate A, Arandjelovic G, Tosato $F$, Bassi P. Do weather conditions influence the onset of renal colic? A novel approach to analysis. Urol Int 2008;80:19-25. 
15. Chauhan V, Eskin B, Allegra JR, Cochrane DG. Effect of season, age, and gender on renal colic incidence. Am J Emerg Med. 2004;22:560-3. [CrossRef]

16. Pincus S, Macbean C, Taylor D. The effects of temperature, age and sex on presentations of renal colic in Melbourne, Australia. Eur J Emerg Med 2010;17:328-31. [CrossRef]

17. al-Hadramy MS. Seasonal variations of urinary stone colic in Arabia. J Pak Med Assoc 1997;47:281-4.

18. Luján M, Sánchez MT, Turo J, Pascual C, Chiva V, Martín C, et al. Climate and epidemiological characteristics of renal colic attendances in an urban setting in Spain. Actas Urol Esp 2011;35:481-6. [CrossRef]

19. Al-Dabbagh TQ, Fahadi K. Seasonal variations in the incidence of ureteric colic. Br J Urol 1977;49:269-75. [CrossRef]

20. Basiri A, Moghaddam SM, Khoddam R, Nejad ST, Hakimi A. Monthly variations of urinary stone colic in Iran and its rela- tionship to the fasting month of Ramadan. J Pak Med Assoc 2004;54:6-8.

21. Cervellin G, Comelli I, Comelli D, Cortellini P, Lippi G, Meschi $T$, et al. Regional short-term climate variations influence on the number of visits for renal colic in a large urban Emergency Department: results of a 7-year survey. Intern Emerg Med 2011;6:141-7. [CrossRef]

22. Brikowski TH, Lotan Y, Pearle MS. Climate-related increase in the prevalence of urolithiasis in the United States. Proc Natl Acad Sci USA 2008;105:9841-6. [CrossRef]

23. Evans K, Costabile RA. Time to development of symptomatic urinary calculi in a high risk environment. J Urol 2005;173:85861. [CrossRef]

24. Atescelik M, Yilmaz M, Gurger M, Yildiz M. The effect of meteorological parameters on the number of renal colic patients. Urolithiasis 2015;43:331-7. [CrossRef] 